\title{
Identification of QTL with effects on intramuscular fat content and fatty acid composition in a Duroc $\times$ Large White cross Marie-Pierre Sanchez ${ }^{1}$, Nathalie Iannuccelli ${ }^{2}$, Benjamin Basso ${ }^{1}$, Jean- Pierre Bidanel ${ }^{1}$, Yvon Billon ${ }^{3}$, Gilles Gandemer ${ }^{4}$, Hélène Gilbert ${ }^{1}$, Catherine Larzul*1, Christian Legault ${ }^{1}$, Juliette Riquet ${ }^{2}$, Denis Milan² and Pascale Le Roy ${ }^{5}$
}

Address: ${ }^{1}$ INRA, UR337 Station de génétique quantitative et appliquée, F-78350 Jouy-en-Josas, France, 2INRA, UR444 Laboratoire de génétique cellulaire, F-31320 Castanet-Tolosan, France, '3INRA, UE967 Génétique expérimentale en productions animales, F-17700 Surgères, France, ${ }^{4}$ INRA, UAR2 Services déconcentrés d'appui à la recherche - Poitou-Charentes, F-17700 Surgères, France and 5INRA-Agrocampus Rennes, UMR598 Génétique animale, F-35042 Rennes, France

Email: Marie-Pierre Sanchez - marie-pierre.sanchez@jouy.inra.fr; Nathalie Iannuccelli - nathalie.iannuccelli@toulouse.inra.fr; Benjamin Basso - benjamin.basso@toulouse.inra.fr; Jean-Pierre Bidanel - jean-pierre.bidanel@jouy.inra.fr;

Yvon Billon - yvon.billon@magneraud.inra.fr; Gilles Gandemer - gilles.gandemer@lusignan.inra.fr; Hélène Gilbert - helene.gilbert@jouy.inra.fr; Catherine Larzul* - catherine.larzul@jouy.inra.fr; Christian Legault - catherine.larzul@jouy.inra.fr;

Juliette Riquet - juliette.riquet@toulouse.inra.fr; Denis Milan - denis.milan@toulouse.inra.fr; Pascale Le Roy - pascale.leroy@rennes.inra.fr

* Corresponding author

Published: 16 August 2007

BMC Genetics 2007, 8:55 doi:10.1/86/147/-2156-8-55
Received: 5 March 2007

Accepted: 16 August 2007

This article is available from: http://www.biomedcentral.com/I47I-2/56/8/55

(C) 2007 Sanchez et al; licensee BioMed Central Ltd.

This is an Open Access article distributed under the terms of the Creative Commons Attribution License (http://creativecommons.org/licenses/by/2.0), which permits unrestricted use, distribution, and reproduction in any medium, provided the original work is properly cited.

\begin{abstract}
Background: Improving pork quality can be done by increasing intramuscular fat (IMF) content. This trait is influenced by quantitative trait loci (QTL) sought out in different pig populations. Considering the high IMF content observed in the Duroc pig, it was appealing to determine whether favourable alleles at a major gene or QTL could be found. The detection was performed in an experimental F2 Duroc $\times$ Large White population first by segregation analysis, then by QTL mapping using additional molecular information.

Results: Segregation analysis provided evidence for a major gene, with a recessive Duroc allele increasing IMF by I.8\% in Duroc homozygous pigs. However, results depended on whether data were normalised or not. After Box-Cox transformation, likelihood ratio was indeed 12 times lower and no longer significant. The QTL detection results were partly consistent with the segregation analysis. Three QTL significant at the chromosome wide level were evidenced. Two QTL, located on chromosomes 13 and 15, showed a high IMF Duroc recessive allele with an overall effect slightly lower than that expected from segregation analysis (+0.4 g/l00 g muscle). The third QTL was located on chromosome I, with a dominant Large White allele inducing high IMF content ( $+0.5 \mathrm{~g} / 100 \mathrm{~g}$ muscle). Additional QTL were detected for muscular fatty acid composition.

Conclusion: The study presented results from two complementary approaches, a segregation analysis and a QTL detection, to seek out genes involved in the higher IMF content observed in the Duroc population. Discrepancies between both methods might be partially explained by the existence of at least two QTL with similar characteristics located on two different chromosomes for which different boars were heterozygous. The favourable and dominant allele detected in the Large White population was unexpected. Obviously, in both populations, the favourable alleles inducing high IMF content were not fixed and improving IMF by fixing favourable alleles using markers can then be applied both in Duroc and LW populations. With QTL affecting fatty acid composition, combining an increase of IMF content enhancing monounsaturated fatty acid percentage would be of great interest.
\end{abstract}




\section{Background}

In the pig, intramuscular fat content (IMF) is considered to play a key role in organoleptic meat quality[1]. The increase of IMF is associated with an improvement in consumer perception of texture and taste [2]. Thus, in Large White and Landrace breeds, increasing IMF content, at least in the Longissimus dorsi muscle, is considered as highly desirable. Additionally, not only the amount of IMF has to be considered but also fatty acid composition, which is known to affect human health and also technological quality of fresh meat and sensory quality of pig meat products.

The existence of a gene with a great effect on IMF content was postulated by segregation analysis [3] in a Chinese European population. The gene, named MI, has a recessive allele (imf) that increases IMF content and originates from the Chinese Meishan breed. Duroc pigs, as well as Meishan pigs, are known for their high IMF content [4]. Moreover, in contrast to the Chinese pigs, Duroc animals have good performances of growth and body composition [5]. A previous analysis indicated the presence of a major gene affecting IMF content in Duroc population [6].

More recently, studies involving Duroc pigs have demonstrated the existence of a quantitative trait locus (QTL) affecting IMF located on chromosome 6 [7-9] but without mentioning a significant dominant/recessive effect. Other locations have also been reported for QTL affecting IMF content in different breeds [10-12].

The objective of the present work was to test the presence of a major gene affecting IMF content in a Duroc population using segregation analysis. Furthermore, molecular analysis has been performed on the same experimental animals in order to locate the putative gene on the pig genome and map QTL affecting fatty acid composition. For that purpose, an F2 resource population was created from Large White and Duroc pigs and measured for IMF characteristics.

\section{Results}

\section{Segregation analysis}

Segregation analysis, either with or without transformation of the data, revealed the presence of a recessive allele with a major effect on IMF content (Table 1). The mean difference between homozygous was estimated to be $1.5 \%$, i.e. 2.1 phenotypic standard deviations. It should be noted that correction for skewness strongly decreased the likelihood ratio. When data were transformed, likelihood ratio was indeed 12 times lower and not significant anymore. The difference between homozygous dropped to $0.86 \%$ ( 1.2 phenotypic standard deviations). Estimated genotype frequencies revealed that only half the F1 breeding animals were heterozygous.

\section{Detection of QTL}

QTL analyses showed 3 chromosome-wide QTL affecting IMF content on chromosomes 1, 13 and 15 (Table 2). On SSC1, the allele responsible for an increased IMF content was dominant and from Large White origin. For the other two QTL on chromosomes 13 and 15, alleles responsible for an increased IMF were recessive and from Duroc origin. The favourable effect was of the same range for the three QTL.

Table 3 shows the location of significant QTL (at least at the chromosome-wide level) and their genetic effects on fatty acid composition. Only 4 QTL out of 47 were significant $(\mathrm{P}<1 \%)$ at the genome-wide level, 3 located at similar positions on chromosome 14. The effect of alleles appeared to be additive. The Duroc/Duroc homozygous pigs had a lower percentage of C16:1, a higher percentage of C18:0, a higher percentage of saturated fatty acids and a higher chain length coefficient. The presence of pleiotropic QTL remains to be tested. QTL $(\mathrm{p}<0.1 \%$ at the

Table I: Results from the segregation analysis

\begin{tabular}{lcccccccc}
\hline Parameters & $\mu_{\text {imflimf }}$ & $\mu_{\text {imf/MF }}$ & $\mu_{\text {IMF/MF }}$ & $\sigma_{\mathrm{e}}$ & $\sigma_{\mathrm{g}}$ & $P_{\text {imf/imf }}$ & $P_{\text {imf/MF }}$ & $L R$ \\
\hline $\begin{array}{l}\text { Without } \\
\text { Box-Cox } \\
\text { transformati } \\
\text { on }\end{array}$ & 0.40 & -1.10 & -1.10 & 0.54 & 0.18 & 0.41 & 0.59 & 36.9 \\
$\begin{array}{l}\text { With Box- } \\
\text { Cox } \\
\text { transformati } \\
\text { on }\end{array}$ & 1.56 & 0.70 & 0.70 & 0.53 & 0.20 & 0.39 & 0.61 & 3.1 \\
\end{tabular}

$\mu_{\text {imf/imf }}, \mu_{\mathrm{imf} / I M F}$ and $\mu_{\mathrm{IMF} / \mathrm{MF}}=$ means of imflimf, imf/IMF and IMF/IMF genotypes in $\mathrm{g} / 100 \mathrm{~g}$ muscle, respectively, imf being the Duroc favourable allele; $\sigma_{\mathrm{e}}=$ residual standard deviation; $\sigma_{\mathrm{g}}=$ genetic standard deviation; Pimflimf and Pimf $/ I M F=$ genotype frequencies of $A A$ and $A B$, respectively; $L R=$ likelihood ratio; $P=$ level of significance. 
Table 2: Results from the detection of QTLs with an effect on IMF

\begin{tabular}{|c|c|c|c|c|c|c|}
\hline \multirow[t]{2}{*}{ SSC } & \multirow{2}{*}{$\begin{array}{c}\text { Maximum } \\
\text { likelihood ratio }\end{array}$} & \multirow[t]{2}{*}{ Location (cM) } & \multicolumn{3}{|c|}{ Genotypic means (\%) } & \multirow{2}{*}{$\begin{array}{c}\text { Heterozygous } \\
\text { boars (likelihood > } \\
\text { 3.8, Khi2 with I } \\
\text { DF) }\end{array}$} \\
\hline & & & $\mathrm{Du} / \mathrm{Du}$ & Du/LW & LW/LW & \\
\hline I & $16.4(++)$ & 16 & -0.34 & 0.15 & 0.19 & Boar 4 \\
\hline 13 & $10.6(+)$ & 52 & 0.27 & -0.09 & -0.18 & Boar 5 \\
\hline 15 & $11.9(+)$ & 50 & 0.29 & -0.12 & -0.17 & Boar I, Boar 4 \\
\hline
\end{tabular}

Maximum likelihood ratio significant at the $5 \%(+)$ or $1 \%(++)$ at the chromosome-wide level

chromosome-wide level) were also found on chromosomes $7,9,10$, and 15 .

\section{Discussion \\ Segregation analysis}

The segregation analysis results illustrated the lack of robustness of segregation analysis in the presence of a skewed distribution. However, the decreased power of the analysis after the Box-Cox transformation has already been demonstrated [13]. The recessive allele, detected in the Duroc breed, had the same characteristics as the one detected in Meishan pigs [3]. The difference between homozygous pigs, obtained from non-transformed data, was indeed $2.1 \%$, i.e. close to the value obtained here $(1.5 \%)$.

\section{Detection of QTL}

The detection of 3 QTL with effects of the same magnitude (difference between homozygous $=0.49,0.43$ and 0.44 phenotypic standard deviation for SSC1, SSC13 and SSC15, respectively) was unexpected. Moreover, one of the QTL was found to have a Large White favourable and dominant allele. The segregation analysis suggested the existence of only one large QTL with a favourable and recessive Duroc allele. In the segregation analysis, only 3 out of the 6 sires were probably heterozygous for the putative major gene. From these 3, 2 were also found heterozygous in the QTL detection. Boar 4 was not found heterozygous in the segregation analysis but was found to be heterozygous for both loci on SSC1 and SSC15 which showed opposite effects depending on the breed origin. Thus, it seemed that the major gene detected with the segregation analysis corresponded to the 2 QTL detected on chromosomes 13 and 15 . The characteristics estimated from the QTL analysis were consistent with the segregation analysis even though their individual effects were weaker than the effect estimated previously. In a similar way, Janss et al (1997) [3] did not locate one single QTL affecting IMF content in their crossbreeding experiment. If they evidenced one major gene by segregation analysis, afterwards they located several small QTL with reduced individual effects.
The chromosome 1 QTL could not have been detected by segregation analysis because only one boar could be considered as heterozygous for this QTL, which was also heterozygous for the QTL on SSC15.

These QTL locations did not correspond to QTL locations generally reported in the literature for related traits. QTL mapping involving the Meishan breed located QTL for intramuscular fat content on SSC2, SSC4, SSC6, SSC7 and SSCX $[10,12,14]$. Two studies involving the Duroc breed $[7,8]$ did not evidence a Duroc recessive allele because they involved backcross design. A QTL was located on chromosome 13 in an F2 Meishan $\times$ Duroc population [14], at position $117 \mathrm{cM}$ with a favourable recessive Duroc allele (additive effect $=0.95 \%)$. Stearns et al (2005) [15] evidenced a QTL on chromosome 13 with an additive effect at $88 \mathrm{cM}$, the allele inherited from the Duroc line being associated to higher lipid content. Rohrer et al (2005) [16] also mentioned a suggestive QTL (without any further details) for intramuscular fat content on chromosome 13 in a Duroc $\times$ Landrace F2 population at 53 $\mathrm{cM}$. They reported, at the same location, a dominant QTL for moisture content, with the Duroc allele associated to lower moisture content. Knowing the high negative correlation between moisture and lipid content, it should be assumed that for lipid content, the QTL would also be dominant with a Duroc allele associated with a higher intramuscular fat content. Additionally to the present study, extensive muscular characteristics were measured on a subset of F2 animals with extreme IMF content [17]. The two groups essentially differed by the number of muscular adipocytes. Previously, it was observed that Duroc and Landrace pigs might show clear differences in peroxisome proliferator-activated receptor gamma $(P P A R \gamma)$ expression [18]. Furthermore, the PPAR $\gamma$ gene maps to porcine chromosome 13 [19]. Unfortunately, Grindflek et al (2004) [20] did not evidence any association between $P P A R \gamma$ polymorphism and IMF content, but the studied populations would fail to fit an association with a recessive Duroc allele. Kim et al (2004) [21] studying Landrace, Large White, Duroc, Berkshire and synthetic Duroc $\times$ Large White populations failed to find any polymorphism 
Table 3: Results of detection of QTLs affecting fatty acids composition

\begin{tabular}{|c|c|c|c|c|c|c|c|}
\hline \multirow[b]{2}{*}{ SSC } & \multirow[b]{2}{*}{ Trait $^{\prime}$} & \multirow[b]{2}{*}{$\mathrm{P}^{2}$} & \multirow{2}{*}{$\begin{array}{l}\text { Position } \\
\text { (cM) }\end{array}$} & \multirow[t]{2}{*}{$\mathrm{LR}^{3}$} & \multicolumn{3}{|c|}{ Genotypic mean (\%) } \\
\hline & & & & & $\mathrm{Du} / \mathrm{Du}$ & Du/LW & LW/LW \\
\hline 1 & CI8:I & + & 124 & 11.2 & -0.79 & 0.36 & 0.43 \\
\hline 1 & CI8:2n-6 & ++ & 29 & 16.0 & 0.82 & 0.02 & -0.84 \\
\hline 1 & MUFA & + & 122 & 13.0 & -0.93 & 0.38 & 0.55 \\
\hline 1 & P:S & + & 29 & 12.4 & 3.90 & -0.30 & -3.60 \\
\hline 2 & $C 22: 5 n-6$ & + & 122 & 12.4 & -0.03 & -0.02 & 0.05 \\
\hline 4 & $C 22: 5 n-6$ & + & 117 & 12.9 & -0.01 & -0.03 & 0.04 \\
\hline 5 & MUFA & + & 118 & 11.0 & -0.49 & -0.27 & 0.76 \\
\hline 7 & CI8:I & + & 66 & 13.9 & 0.43 & 0.51 & -0.94 \\
\hline 7 & $C 18: 2 n-6$ & + & 60 & 15.0 & -0.54 & -0.37 & 0.91 \\
\hline 7 & $C 22: 4 n-6$ & ++ & 48 & 17.5 & -0.04 & -0.01 & 0.05 \\
\hline 7 & C22:5 & $*$ & 48 & 18.5 & -0.05 & 0.00 & 0.05 \\
\hline 7 & CLC & + & 46 & 12.5 & -0.02 & -0.07 & 0.09 \\
\hline 8 & $\mathrm{Cl} 6: 0$ & + & 66 & 14.1 & -0.27 & 0.42 & -0.14 \\
\hline 9 & $\mathrm{Cl} 4: 0$ & + & 27 & 11.1 & 0.07 & -0.05 & -0.02 \\
\hline 9 & $\mathrm{Cl} 8: 0$ & + & 14 & 10.8 & -0.31 & 0.09 & 0.22 \\
\hline 9 & $C 20: 3$ & $*$ & 88 & 18.3 & 0.01 & 0.03 & -0.04 \\
\hline 10 & Cl6:I & + & 106 & 12.7 & 0.12 & 0.03 & -0.15 \\
\hline 10 & CI8:I & + & 103 & 13.4 & 0.62 & 0.34 & -0.96 \\
\hline 10 & $C 18: 2 n-6$ & + & 108 & 11.1 & -0.43 & -0.40 & 0.83 \\
\hline 10 & C20:5 & $*$ & 27 & 17.4 & 0.01 & -0.04 & 0.03 \\
\hline 10 & $C 22: 5 n-6$ & ++ & 42 & 15.3 & -0.01 & -0.02 & 0.04 \\
\hline 10 & MUFA & $*$ & 41 & 15.9 & 0.02 & 0.71 & -0.73 \\
\hline 10 & UC & + & 42 & 11.6 & 0.00 & -0.02 & 0.02 \\
\hline 11 & CI7:I & + & 92 & 12.4 & -0.01 & -0.09 & 0.11 \\
\hline 11 & $C 22: 6 n-3$ & ++ & 51 & 15.2 & 0.03 & -0.01 & -0.02 \\
\hline 11 & PUFA & + & 89 & 13.6 & 1.41 & -0.62 & -0.80 \\
\hline 11 & $\mathrm{P}: \mathrm{S}$ & + & 63 & 13.2 & 4.73 & -2.11 & -2.62 \\
\hline 11 & UC & + & 65 & 11.6 & 0.04 & -0.02 & -0.01 \\
\hline 12 & $\mathrm{Cl} 6: \mathrm{I}$ & + & 40 & 11.6 & -0.12 & 0.05 & 0.07 \\
\hline 13 & CI8:I & + & 45 & 12.2 & 0.81 & -0.45 & -0.36 \\
\hline 13 & $C 22: 5 n-6$ & + & 102 & 12.7 & -0.02 & -0.03 & 0.05 \\
\hline 13 & MUFA & + & 45 & 14.6 & 0.96 & -0.62 & -0.34 \\
\hline 14 & $\mathrm{Cl} 6: 0$ & + & 22 & 14.6 & -0.07 & 0.33 & -0.26 \\
\hline 14 & CI6:I & $* *$ & 67 & 22.0 & -0.19 & 0.04 & 0.15 \\
\hline 14 & CI8:0 & $* * *$ & 67 & 32.9 & 0.51 & -0.09 & -0.43 \\
\hline 14 & $C 18: 2 n-6$ & + & 22 & 13.2 & 0.42 & -0.78 & 0.36 \\
\hline 14 & $C 20: 3 n-3$ & ++ & 21 & 14.9 & 0.02 & -0.03 & 0.01 \\
\hline 14 & $C 22: 5 n-6$ & + & 32 & 22.2 & 0.02 & -0.03 & 0.01 \\
\hline 14 & SFA & $* *$ & 45 & 23.7 & 0.62 & 0.11 & -0.73 \\
\hline 14 & MUFA & + & 67 & 12.3 & -1.02 & 0.36 & 0.65 \\
\hline 14 & PUFA & + & 23 & 12.6 & 0.73 & -1.19 & 0.46 \\
\hline 14 & P:S & ++ & 23 & 15.2 & 1.75 & -4.06 & 2.30 \\
\hline 14 & UC & + & 26 & 12.6 & 0.02 & -0.03 & 0.01 \\
\hline 14 & CLC & $* *$ & 65 & 23.4 & 0.13 & -0.04 & -0.09 \\
\hline 15 & CI4:0 & $*$ & 44 & 18.4 & 0.08 & -0.10 & 0.03 \\
\hline 16 & $\mathrm{Cl} 6: 0$ & + & 33 & 12.7 & -0.13 & -0.26 & 0.39 \\
\hline 18 & $C 20: 5 n-3$ & + & 7 & 11.9 & -0.01 & 0.03 & -0.01 \\
\hline
\end{tabular}

IPercentages of saturated (SFA), monounsaturated (MUFA) and polyunsaturated (PUFA) fatty acids, unsaturation coefficient (UC), chain length coefficient (CLC), ratio of polyunsaturated fatty acids to saturated fatty acids (P:S); 2 Maximum likelihood ratio significant at the $5 \%(+)$ or $1 \%(++)$ at the chromosome-wide level and in bold $5 \%(*), 1 \%\left({ }^{* *}\right)$ or $0.1 \%(* * *)$ at the genome wide level; ${ }^{3}$ LR: Maximum likelihood ratio

in the PPAR $\gamma$ gene. However, these authors suggested an association between marbling score and polymorphism in the GHRL gene, mapped close to PPAR $\gamma$ on chromosome 13, in a Berkshire population.
Considering the two QTL located on SSC1 and SSC15, some studies with different breeds showed similar results. A partially dominant Yorkshire allele with an increasing effect on IMF content has been detected in an F2 Berkshire 
Table 4: Means (in \%) and Standard deviation (SD) of data

\begin{tabular}{|c|c|c|c|}
\hline Variable & Label & Mean & SD \\
\hline cl $4: 0$ & Myristic acid & 0.68 & 0.54 \\
\hline cl6:0 & Palmitic acid & 23.4 & 1.3 \\
\hline cl6:I & Palmitoleic acid & 2.85 & 0.55 \\
\hline cl7:I & Heptadecaenoic acid & 0.429 & 0.820 \\
\hline cl8:0 & Stearic acid & 11.8 & 1.3 \\
\hline c|8:I & Oleic acid & 38.8 & 3.2 \\
\hline cl8:2n-6 & Linoleic acid & 15.7 & 2.6 \\
\hline cl $8: 3 n-3$ & Linolenic acid & 0.717 & 0.303 \\
\hline$c 20: 0$ & Arachidic acid & 0.154 & 0.091 \\
\hline c20:1 & Eicosaenoic acid & 0.566 & 0.145 \\
\hline $\mathrm{c} 20: 2$ & Eicosadienoic acid & 0.517 & 0.117 \\
\hline$c 20: 3 n-6$ & Di-homo $\gamma$ linolenic & 0.337 & 0.136 \\
\hline$c 20: 4 n-6$ & Arachidonic acid & 2.79 & 0.80 \\
\hline$c 20: 5 n-3$ & Eicosapentaenoic acid (EPA) & 0.171 & 0.107 \\
\hline$c 22: 4 n-6$ & Docosatetraenoic acid & 0.420 & 0.142 \\
\hline$c 22: 5 n-6$ & Docosapentaenoic acid & 0.455 & 0.147 \\
\hline$c 22: 6 n-3$ & Docosahexaneoic acid (DHA) & 0.186 & 0.100 \\
\hline SFA & $\%$ saturated fatty acids & 36.1 & 2.0 \\
\hline MUFA & $\%$ monounsaturated fatty acids & 42.6 & 3.5 \\
\hline PUFA & $\%$ polyunsaturated fatty acids & 21.6 & 3.8 \\
\hline$P: S$ & Polyunsaturated to saturated ratio & 0.604 & 0.122 \\
\hline INSAT & Unsaturation coefficient & 1.50 & 0.10 \\
\hline CLC & Chain length coefficient & 17.6 & 0.06 \\
\hline IMF & Intramuscular Fat & 2.03 & 0.67 \\
\hline
\end{tabular}

$\times$ Yorkshire population. It was located on chromosome 1 , at $16 \mathrm{cM}$ [22]. As shown by [16] on SSC4 in a Landrace $\times$ Duroc crossbreeding, recessive allele associated with high intramuscular fat content could also be found in Landrace. Two QTL affecting IMF content were located on chromosome 15, at 42 and $57 \mathrm{cM}$, in an F2 wild boar $\times$ Large White cross [23]. For that QTL, the dominance effect was very low and as expected the Large White allele increased IMF content.

The most significant QTL were linked to fatty acid composition. Location of several QTL was to be expected considering the high heritability values of fatty acid traits [24]. Previous studies reported QTL on fatty acid composition measured in the backfat $[25,26]$ but the present study is the first one to present QTL on fatty acid composition measured in pig meat. In [25], QTL were found on chromosomes 4, 6, 8, 10 and 12. In [26], they found QTL on chromosomes 1, 2, 3, 4, 5, 6, 9, 14, 15, 16, 17 and X. Considering the low genetic correlations between muscle and backfat characteristics [24], QTL were expected to be different. As mentioned by [27] in pigs, fatty acid composition is altered by food composition. The polyunsaturated linoleic and $\alpha$-linolenic fatty acids cannot be synthesised in situ, thus tissue concentrations respond rapidly to dietary changes. In contrast, saturated and monounsaturated fatty acids are de novo synthesised, hence their concentrations are less readily influenced by diet. Fatty acid compo- sition is also influenced by genetic background. Duroc pigs have a higher concentration of saturated and monounsaturated fatty acids than Landrace pigs [28]. QTL located on SSC14 showed an increase of saturated fatty acids associated with a Duroc allele. Interestingly, a suggestive QTL located on the same chromosome affecting monounsaturated fatty acid showed a Duroc allele associated to a lower concentration of monounsaturated fatty acids. A model fitting one pleiotropic or two QTL should be performed to determine if this is the same QTL. On SSC13, close to one of the IMF QTL, the suggestive QTL affecting the concentration of monounsaturated fatty acids showed a Duroc allele associated to a favourable but recessive effect. The existence of one or two different QTL has to be tested. Location of the QTL detected on SSC12 should be considered with cautious because no genotype information was available at the extreme of the chromosome.

Influencing fatty acid composition could be of interest considering pork nutritional quality, especially those influencing mono- and polyunsaturated fatty acids. It is known that a higher percentage of polyunsaturated fatty acids leads to a meat of inferior quality. This might be related to softness and oxidation phenomena, producing off-flavours and rancidity in meat. From a dietary point of view, a lower percentage of saturated fatty acids is considered as beneficial, because the main fatty acids behind the 


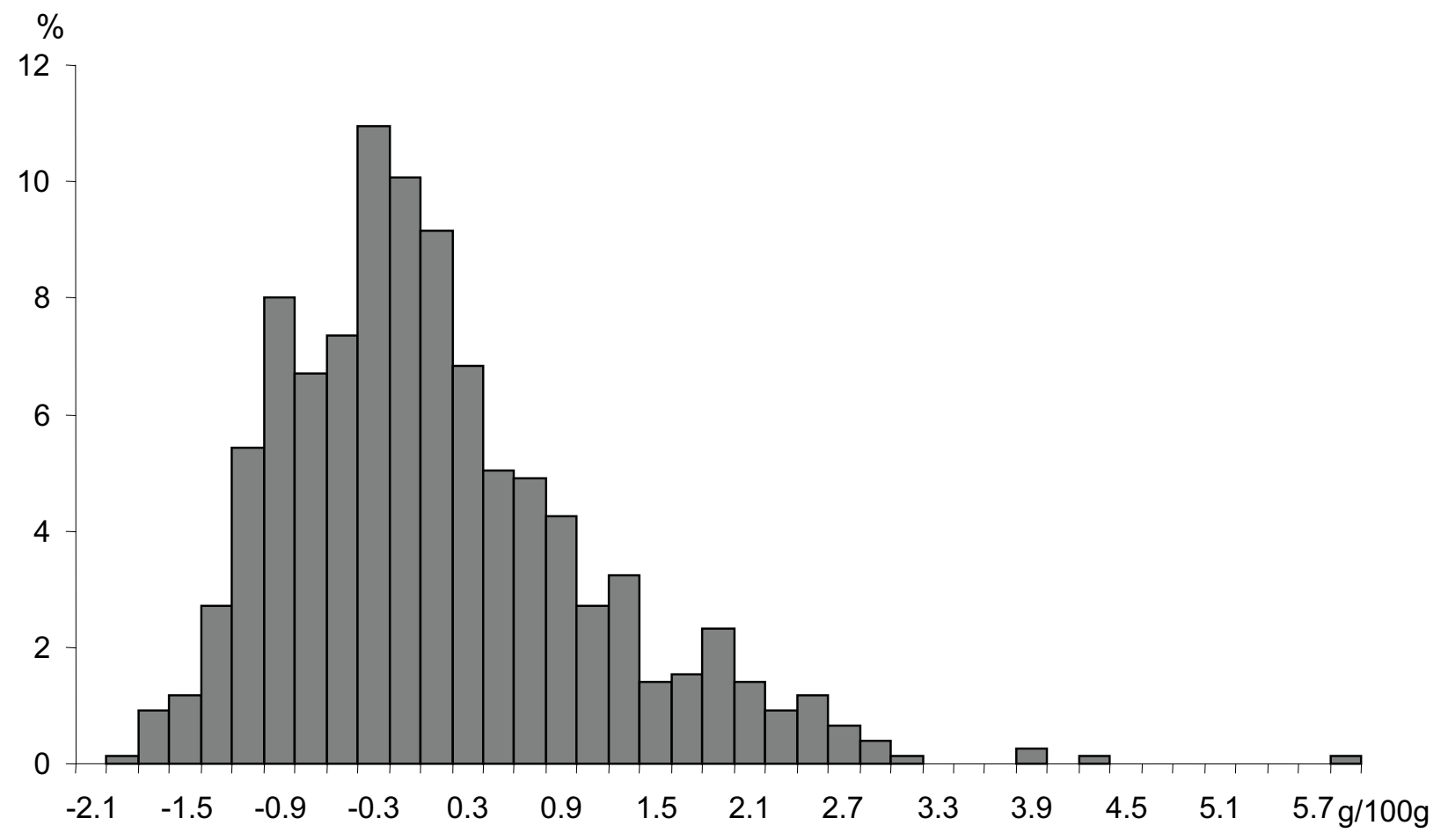

Figure I

Distribution of adjusted intramuscular content in the F2 Duroc $\times$ Large White population.

cholesterol elevating effect are C14:0 and C16:0. Combining an increase of IMF content enhancing monounsaturated fatty acid percentage would be of great interest.

\section{Conclusion}

The present study indicated a complementary approach of a segregation analysis and a QTL detection to seek out genes involved in the higher IMF content observed in the Duroc population. Discrepancy between both methods might be partially explained by the existence of at least two QTL with the same properties located on two different chromosomes for which different boars were heterozygous. The favourable and dominant allele detected in the Large White population was completely unexpected. In both populations, the favourable alleles inducing high IMF content were not fixed. Improving IMF by fixing favourable alleles using markers can then be applied both in Duroc and LW populations. However, a more accurate location should be performed before. Additionally, this study provided for the first time evidence for QTL on mus- cle fatty acid composition, with leads to modify both IMF content and monounsaturated fatty acid percentage.

\section{Methods \\ Animals}

An F2 cross between Duroc and Large White pigs was performed at the INRA experimental farm of Le Magneraud (Charente-Maritime, France). A total of 204 Duroc pigs (117 boars and 87 sows) issued from the nucleus herd of Selpa (Alliers, France) was measured for IMF content. Among these Duroc animals, 8 boars with high IMF content values (from 3.3 to $5.8 \%$ ) were selected and mated to 37 Large White sows (F0 generation). Among F1 animals, 10 sires and 32 dams were randomly selected to produce the next generation. Each F1 dam produced 3 litters with the same boar and a total of 775 F2 pigs were generated. All the F2 piglets were weaned at 28 days of age and placed in post weaning collective pens until 10 weeks of age. 
Table 5: Location of markers

\begin{tabular}{|c|c|c|c|c|c|c|c|c|}
\hline & $\mathrm{Chr}$ & cM & & Chr & cM & & $\mathrm{Chr}$ & $c M$ \\
\hline SW552 & I & 9 & S0383 & 7 & 0 & SWI307 & 12 & 40 \\
\hline S0008 & I & 44 & S0025 & 7 & 24 & SW874 & 12 & 63 \\
\hline S0396 & 1 & 60 & SWI354 & 7 & 42 & S0090 & 12 & 80 \\
\hline SOI55 & I & 95 & LRAI & 7 & 75 & SW2180 & 12 & 105 \\
\hline SWI828 & I & 120 & SOI02 & 7 & 90 & SWRI94I & 13 & 14 \\
\hline SWI30I & I & 140 & SW352 & 7 & 108 & S0222 & 13 & 45 \\
\hline SWC9 & 2 & 1.1 & SW632 & 7 & 125 & SW225 & 13 & 70 \\
\hline SW2623 & 2 & 10 & SOIOI & 7 & 155 & SW38 & 13 & 102 \\
\hline SW240 & 2 & 41 & SW764 & 7 & 175 & SW857 & 14 & 8 \\
\hline S0226 & 2 & 79 & SW24I0 & 8 & 1 & S0058 & 14 & 32 \\
\hline S0368 & 2 & 105 & SW905 & 8 & 20 & S0007 & 14 & 60 \\
\hline S0036 & 2 & 132 & SWRIIOI & 8 & 37 & SW55 & 14 & 80 \\
\hline SW72 & 3 & 17 & SWI843 & 8 & 53 & SW25I5 & 14 & 108 \\
\hline SW487 & 3 & 42 & SWI55I & 8 & 106 & SWIIII & 15 & 27 \\
\hline SWI02 & 3 & 65 & S0178 & 8 & 127 & S0088 & 15 & 53 \\
\hline S0372 & 3 & 95 & SW983 & 9 & I & SW936 & 15 & 79.4 \\
\hline S0397 & 3 & 110 & sW9II & 9 & 32 & SOIII & 16 & 1 \\
\hline SW2547 & 4 & 30 & SW940 & 9 & 57 & SW24II & 16 & 17 \\
\hline SW839 & 4 & 62.1 & SWI677 & 9 & 76 & S0026 & 16 & 47 \\
\hline $\mathrm{SO} / 4$ & 4 & 80 & SW2093 & 9 & 100 & SWI897 & 16 & 86 \\
\hline SW445 & 4 & 105 & SW2116 & 9 & 126 & SW24 & 17 & 23 \\
\hline S0097 & 4 & 120 & SWRI36 & 10 & 8 & SW244I & 17 & 41 \\
\hline SWI 482 & 5 & 39 & SW249I & 10 & 42 & SWI920 & 17 & 56 \\
\hline SW 2425 & 5 & 72 & S0070 & 10 & 62 & S0359 & 17 & 75 \\
\hline SWI 987 & 5 & 102 & SW95I & 10 & 95 & SW2540 & 18 & 2 \\
\hline IGFI & 5 & 118 & SWR67 & 10 & 121 & SWI984 & 18 & 30 \\
\hline SW378 & 5 & 133 & S0392 & II & 3 & SOI 20 & 18 & 45 \\
\hline SWI353 & 6 & 29 & SWI632 & 11 & 16 & SW980 & $x$ & 11 \\
\hline S0087 & 6 & 62 & S0382 & 11 & 52 & SWI903 & $x$ & 32 \\
\hline SWI22 & 6 & 84 & SWI377 & 11 & 76 & SW2456 & $x$ & 58 \\
\hline S0228 & 6 & 105 & SWII35 & 11 & 100 & SWI994 & $x$ & 75 \\
\hline SOI2I & 6 & 116 & & & & SWI943 & $x$ & 87 \\
\hline SW 2419 & 6 & 161 & & & & $\mathrm{~S} 0218$ & $x$ & 115 \\
\hline
\end{tabular}

\section{Intramuscular fat measurements}

IMF content was measured in Duroc, F1 and F2 animals. At a live weight of $70 \mathrm{~kg}$, a muscle sample was taken by biopsy from the longissimus dorsi muscle at the level of the last rib. Lipids were extracted from $1 \mathrm{~g}$ samples [29] and weighed. IMF content is expressed in $\mathrm{g} / 100 \mathrm{~g}$ muscle. All analyses were done in duplicate. Mean results from the two samples analysed were used for statistical analyses (Table 4).

The fatty acid composition of lipid fractions was determined by gas-liquid chromatography of methyl esters [30]. Fatty acid composition was expressed in \% total fatty acids. The following parameters were calculated from fatty acid composition:

- the sum of saturated, monounsaturated and polyunsaturated fatty acids;
- the ratio of polyunsaturated fatty acids to saturated fatty acids;

- the unsaturation coefficient defined as the average number of double bounds of unsaturated fatty acids;

- the chain length coefficient calculated using the formula $\Sigma \mathrm{p}_{\mathrm{i}} \mathrm{c}_{\mathrm{i}} / 100$ where $\mathrm{p}_{\mathrm{i}}$ and $\mathrm{c}_{\mathrm{i}}$ are respectively the percentage and the number of carbon atoms of each fatty acid $i$;

- the ratio of n- 6 fatty acids to n-3 fatty acids.

\section{Molecular analyses}

The 6 F1 boar families with the largest number of offspring were selected for molecular analyses. F1 sires were genotyped for 157 molecular markers. Among these markers, a set of 91 informative markers covering the porcine autosomes (from 3 to 9 markers per chromosome; Table 5) was selected. Some chromosomal ends (4, 5, 6, $12,15)$ were not covered by genotype markers. Thirty-one 
F0 animals, $27 \mathrm{~F} 1$ animals ( 6 boars and 21 sows) and 456 F2 pigs were genotyped for this set of markers using DNA extracted from blood samples.

\section{Statistical analyses}

Prior to segregation (without marker information) or QTL detection (with marker information) analyses, intramuscular fat content and fatty acid composition traits were adjusted for the effects of contemporary group, sex and age at biopsy with the GLM procedure of SAS [31].

First, a segregation analysis was applied to adjusted data [32]. A description of the model used and the details on calculations are given in Sanchez et al. [33]. Briefly, this method was based on the comparison of the likelihood of the data under a mixed model (H1: a major gene + polygenes) and under a polygenic model $(\mathrm{HO})$. We assumed that the data originated from independent sire families. The major gene was modelled as an autosomal biallelic ( $A$ and $B$ ) locus with Mendelian transmission probabilities. Three genotypes could thus be encountered: $A A, A B$ and $B B$. Under $H 1$, the model depended on 7 parameters: $\mu_{A A^{\prime}}$ $\mu_{A B}$ and $\mu_{B B}$ (genotype means), $\sigma_{g}$ and $\sigma_{e}$ (genetic and residual standard deviations, respectively), $P_{A A}$ and $P_{A B}$ (genotype frequencies). $\mathrm{HO}$ was a sub-hypothesis of $\mathrm{H} 1$ and was given by $\mu_{A A}=\mu_{A B}=\mu_{B B}=\mu_{0}$. Under $H 0$, the model thus depended on 3 parameters $\left(\mu_{0}, \sigma_{g}\right.$ and $\left.\sigma_{e}\right)$. The test statistic was a likelihood ratio $l=-2 \ln (\mathrm{MO} / \mathrm{M} 1)$ where $M 1$ and $M 0$ were the maximised likelihoods under $H 1$ and $H O$, respectively. We supposed that the likelihood ratio was asymptotically distributed as a $\chi^{2}$ with 4 degrees of freedom [34].

The F2 distribution of adjusted IMF content appeared strongly skewed (Figure 1, 6). A skewed distribution is indeed expected in F2 when a major gene is segregating with non-additive effect. However, skewness may lead to a false inference of a major gene [13]. In order to resolve between skewness of the trait and segregation at a major locus, penetrance functions were written under $\mathrm{HO}$ and H1 using a Box-Cox transformation [35]. The transformation parameters were estimated jointly with the other model parameters, under both $\mathrm{HO}$ and $\mathrm{H} 1$ hypotheses. In order to test the effect of the Box-Cox transformation on segregation analysis results, segregation analysis was also performed without Box-Cox transformation.

Second, interval mapping analyses were performed to detect QTL using molecular information on adjusted data, with the QTLMAP software developed at INRA [36]. For successive locations, the hypothesis of one QTL (H1) in segregation at the given position was compared to the hypothesis of no QTL (H0) on the chromosome. The model assumed that alternative QTL alleles A and B were fixed in each founder population. Performance distribu- tions were modelled within families, allowing heterogeneity of variance between sire families. Under the H1 hypothesis, a QTL with additive and dominance effects was fitted to the data, so that means of trait distributions depending on the QTL genotype were estimated: $\mu \mathrm{AA}$, $\mu \mathrm{AB}, \mu \mathrm{BB}$. Likelihoods were maximised under each hypothesis, and a likelihood ratio test (L-ratio) was computed for each position tested. Significance thresholds were empirically determined at the chromosome level, by performing simulations under $\mathrm{HO}$, using the assumption of a polygenic infinitesimal model [36]. A total of 5,000 simulations were achieved for each chromosome, and an approximate Bonferroni correction was applied to obtain genome-wide significance levels.

\section{Authors' contributions}

MPS performed statistical analyses (segregation analysis, final QTL detection) and drafted the manuscript. BB performed the first draft of QTL location. YB supervised the performance testing, from animal production to biological sampling. CL helped to draft the manuscript and finalized the writing. HG advised the QTL detection analysis. $\mathrm{NI}$ genotyped F0 and F1 animals to identify informative markers, DM selected markers to screen the whole genome and supervised genotyping work and JR checked haplotypes of fat animals in QTL regions. GG, CLe and JPB participated in the design and the realisation of the experiment. PL had the scientific responsibility and coordinated the whole experiment.

\section{Acknowledgements}

This study was supported by the INRA programme "biological characteristics and meat quality in pigs" and by a grant from the Animal Genetics Department. The authors thank all INRA "pig meat quality" group participants for the brainstorming which contributed to set up this experiment. Thanks are extended to the entire staff of the pig experimental unit in Le Magneraud for animal caretaking, biological sampling, and samples preparation and analyses, especially to Hughes Griffon who took in charge lipid measurements. We would also like to mention Labogena and the CRGS platform of Toulouse Midi-Pyrénées Genopole ${ }^{\circledR}$ for their technical assistance in genotyping.

\section{References}

I. Fernandez X, Monin G, Talmant A, Mourot J, Lebret B: Influence of intramuscular fat content on the quality of pig meat - I. Composition of the lipid fraction and sensory characteristics of m. longissimus lumborum. Meat Sci 1999, 53:59-65.

2. Fernandez X, Monin G, Talmant A, Mourot J, Lebret B: Influence of intramuscular fat content on the quality of pig meat -2 . Consumer acceptability of $\mathbf{m}$. longissimus lumborum. Meat Sci 1999, 53:67-72.

3. Janss LLG, van Arendonk JAM, Brascamp EW: Bayesian statistical analyses for presence of single genes affecting meat quality traits a crossed pig population. Genetics 1997, I 45:395-408.

4. Bout J, Girard JP, Sellier P, Runavot JP: Comparaison de porcs Duroc et Large White pour la composition chimique du gras de bardière et du muscle long dorsal. J Rech Porcine en France 1990, 22:29-34

5. Young LD: Effects of Duroc, Meishan, Fengjing, and Minzhu boars on productivity of mates and growth of first-cross progeny. J Anim Sci 1992, 70:2030-2037. 
6. Sanchez MP, Le Roy P, Griffon H, Caritez JC, Fernandez X, Legaut C, Gandemer G: Déterminisme génétique de la teneur en lipides intramusculaires dans une population F2 Duroc $\times$ Large White. Journ Rech Porc 2000, 34:39-43.

7. Gerbens F, van Erp AJM, Harders FL, Verburg FJ, Meuwissen THE, Veerkamp $J H$, te Pas MFW: Effect of genetic variants of the heart fatty acid-binding protein gene on intramuscular fat and performance traits in pigs. J Anim Sci 1999, 77:846-852.

8. Grindflek E, Szyda J, Liu Z, Lien S: Detection of quantitative trait loci for meat quality in a commercial slaughter pig cross. Mamm Genome 200I, I 2:299-304.

9. Szyda J, Liu Z, Grindflek E, Lien S: Application of a mixed inheritance model to the detection of quantitative trait loci in swine. J Appl Genet 2002, 43:69-84.

10. Hu Z, Dracheva S, Jang W, Maglott D, Bastiaansen J, Rothschild MF Reecy JM: A QTL resource and comparison tool for pigs: PigQTLDB. Mamm Genome 2005, 16:792-800.

II. Sato S, Hasebe H, Sato S, Asahi Y, Hayashi T, Kobayashi E, Sugimoto $Y$ : High-resolution physical mapping and construction of a porcine contig spanning the intramuscular fat content $Q T L$. Anim Genet 2006, 37: I I3-120.

12. Bidanel JP, Milan D, Renard C, Gruand J, Mourot J: Detection of quantitative trait loci for intramuscular fat content and lipogenic enzyme activities in Meishan $\times$ Large White F2 pigs. In Proceeding of the Seventh World Congress on Genetic Applied to Livestock: 19-23 August 2002, Montpellier INRA, CD-ROM Comm 03-13.

13. Demenais F, Lathrop M, Lalouel JM: Robustness and power of the unified model in the analysis of quantitative measurements. Am J Hum Genet 1986, 38:228-234.

14. Sato S, Oyamada Y, Atsuji K, Nade T, Sato SI, Kobayashi E, Mitsuhashi T, Nirasawa K, Komatsuda A, Saito Y, Terai S, Hayashi T, Sugimoto Y: Quantitative trait loci analysis for growth and carcass traits in a Meishan $\times$ Duroc F2 resource population. J Anim Sci 2003, $81: 2938-2949$.

15. Stearns TM, Beever JE, Southey BR, Ellis M, McKeith FK, RodriguezZas SL: Evaluation of approaches to detect quantitative trait loci for growth, carcass and meat quality on swine chromosomes 2, 6, 13 and 18. I. Univariate outbred F2 and sib-pair analyses. J Anim Sci 2005, 83: I48I-I 493.

16. Rohrer GA, Thallman RM, Shackelford S, Wheeler T, Koohmaraie M: A genome scan for loci affecting pork quality in a Duroc $x$ Landrace F2 population. Anim Genet 2005, 37:17-27.

17. Damon M, Louveau I, Lefaucheur L, Lebret $B$, Vincent $A$, Le Roy $P$, Sanchez MP, Herpin P, Gondret F: Number of intramuscular adipocytes and fatty acid binding protein- 4 content are significant indicators of intramuscular fat level in crossbred Large White $\times$ Duroc pigs. J Anim Sci 2006, 84: $1083-1092$.

18. Grindflek $E$, Sundvold $H$, Klungland $H$, Lien $S$ : Characterisation of porcine peroxisome proliferators-activated receptor $\gamma I$ and $\gamma$ 2: detection of breed and age differences in gene expression. Bioch Biophys Res Comm 1998, 249:713-718.

19. Grindflek E, Sundvold H, Lien S, Rothschild MF: Physical and genetic mapping of the peroxisome proliferators receptor $\gamma$ (PPAR $\gamma$ ) gene to porcine chromosome 13. J Anim Sci 2000, 78:1391-1392.

20. Grindflek E, Hoen N, Sundvold H, Rothschild MF, Plastow G, Lien S: Investigation of a peroxisome proliferators-activated receptor gamma haplotype effect on meat quality and carcass traits in pigs. Anim Genet 2004, 35:238-24I.

21. Kim KS, Thomsen H, Bastiaansen J, Nguyen NT, Dekkers JCM, Plastow GS, Rothschild MF: Investigation of obesity candidate genes on porcine fat deposition quantitative trait loci regions. Obes Res 2004, I 2: 1981-1994.

22. Malek M, Dekkers JCM, Lee HK, Baas TJ, Prusa K, Huff-Lonergan E, Rothschild MF: A molecular genome scan analysis to identify chromosomal regions influencing economic traits in the pig. II. Meat and muscle composition. Mamm Genome 200I, 1 2:637-645.

23. Nii M, Hayashi T, Mikawa S, Tani F, Niki A, Mori N, Uchida $Y$, Fujishima-Kanaya N, Komatsu M, Awata T: Quantitative trait loci mapping for meat quality and muscle fiber traits in a Japanese wild boar $\times$ Large White intercross. J Anim Sci 2005, 83:308-3।5.

24. Maignel L, Guéblez R, Bardinal M, Garreau H, Bidanel JP, Sellier P: Paramètres génétiques de la composition de deux dépôts adipeux (bardière et panne) et du muscle Long dorsal chez le porc. J Rech Porcine 1998, 30:73-80.

25. Clop A, Ovilo C, Perez-Encizo M, Cercos A, Tomas A, Fernandez A, Coll A, Folch JM, Barragan C, Diaz I, Oliver MA, Varona L, Silio L, Sanchez A, Noguera JL: Detection of QTL affecting fatty acid composition in the pig. Mamm Genome 2003, 14:650-656.

26. Nii M, Hayashi T, Tani F, Niki A, Mori N, Fujishima-Kanaya N, Komatsu M, Aikawa K, Awata T, Mikawa S: Quantitative trait loci mapping for fatty acid composition traits in perirenal and backfat using Japanese wild boar $\times$ Large white intercross. Anim Genet 2006, 37:342-347.

27. Rosenvold K, Andersen $\mathrm{HJ}$ : Factors of significance for pork quality - a review. Meat Sci 2003, 64:219-237.

28. Cameron ND, Enser MB: Fatty acid composition of lipid in Longissimus dorsi muscle of Duroc and British Landrace pigs and its relationship with eating quality. Meat Sci I991, 29:295-307.

29. Folch J, Lees M, Sloane Stanley GH: A simple methods for the isolation and purification of total lipids from animal tissues. $J$ Biol Chem 1957, 226:497-509.

30. Morrison WR, Smith LM: Preparation of fatty acid methyl esters and dimethylacetals from lipids with boron fluoridemethanol. J Lip Res 1964, 5:600-608.

31. SAS Institute: SAS OnlineDoc ${ }^{\circledR}$ Version 8, Cary, Sas Institute Inc. 1999.

32. Elston RC, Stewart J: A general model for the genetic analysis of pedigree data. Human hered 1971, 21:523-542.

33. Sanchez MP, Bidanel JP, Zhang SQ, Naveau J, Burlot T, Le Roy P: Likelihood and Bayesian analyses reveal major genes affecting body composition, carcass, meat quality and the number of false teats in a Chinese European pig line. Genet Sel Evol 2003, 35:385-402.

34. Le Roy P, Elsen JM, Knott S: Comparison of four statistical methods for detection of a major gene in a progeny test design. Genet Sel Evol 1989, 21:341-357.

35. MacLean CJ, Morton NE, Elston RC, Yee S: Skewness in commingled distributions. Biometrics 1976, 32:695-699.

36. Le Roy P, Elsen JM, Boichard D, Mangin B, Bidanel JP, Goffinet B: An algorithm for QTL detection in mixture of full and half sib families. In Proceeding of the Sixth World Congress on Genetic Applied to Livestock: I I-I 6 July Armidale Volume 26. University of New England; 1996:257-260.

Publish with Bio Med Central and every scientist can read your work free of charge

"BioMed Central will be the most significant development for disseminating the results of biomedical research in our lifetime. "

Sir Paul Nurse, Cancer Research UK

Your research papers will be:

- available free of charge to the entire biomedical community

- peer reviewed and published immediately upon acceptance

- cited in PubMed and archived on PubMed Central

- yours - you keep the copyright 